\title{
The cultivation of Typhonodorum lindleyanum Schott at the Royal Rotterdam Zoological and Botanical Gardens
}

\author{
Louwerens-Jan Nederlof ${ }^{1}$ \& Christopher Lee Degenaar ${ }^{2}$
}

\begin{abstract}
Typhonodorum lindleyanum Schott has been cultivated in the tropical greenhouses of Rotterdam Zoo since 2018. In this article the cultivation of the species is described with reference to its natural environment. This includes information on planting out in a pond heated to tropical temperatures, general maintenance, cultivation to flowering stage and propagation from the resulting seeds. In the process of cultivating this plant the authors believe that further study on the pollination mechanism and flower anatomy of Typhonodorum would be worthwhile, and proposals for this are briefly discussed.
\end{abstract}

\section{Introduction}

The Royal Rotterdam Zoological and Botanical Gardens (Rotterdam Zoo) were founded in 1869 in the centre of the city of Rotterdam, The Netherlands. Since the early stages of the zoo's existence, the dual processes of collecting the plants and the animals have been closely connected. Nowadays, Rotterdam Zoo is one of the most modern zoos in Europe due to its 'eco displays', whereby the unique combination of plants and animals on display plays a major role in the education, research and conservation activities presented to the 1.5 million visitors per year (Wourms, 1990). The zoo is divided into areas each representing a continent - Asia, Africa and Oceania - and contains a tropical greenhouse with neotropical plants and animals called Amazonica. An indoor exhibit, 'Taman Indah', with lowland rainforest flora from Southeast Asia, is shared with Indian elephants. The establishment of a Madagascar display has recently been identified as a priority. With this project for the near future in mind, some plants characteristic of Madagascar have been donated from other botanic gardens and placed in the nursery greenhouses. One of the species planned for the more humid parts of the exhibit, besides the iconic and endangered Adansonia grandidieri, endangered Euphorbia ssp. and several palm species, is Typhonodorum lindleyanum Schott Araceae (water banana). This species has a distribution of Madagascar, Comoros and Mauritius (Mayo et al., 1997). In the wild, Typhonodorum grows in shallow waters, alongside rivers, lakes, ponds and marshy places. Water bananas have a remarkable superficial likeness to the edible banana, Musa sp. in Musaceae, but the genera are not related at all.

Typhonodorum lindleyanum is a gigantic herb that reaches a height of up to $4 \mathrm{~m}$ when mature (Fig. 1). The pseudostem is 1.0 to $1.5 \mathrm{~m}$ high and is formed from the lower parts of the petiole sheaths and those of mature leaves

\footnotetext{
${ }^{1}$ Louwerens-Jan Nederlof is the Curator of Plants at the Royal Rotterdam Zoological and Botanical Gardens. Address: PO Box 532, 3000 AM, The Netherlands.

Email: I.nederlof@rotterdamzoo.nl

${ }^{2}$ Christopher Lee Degenaar is a Senior Indoor Horticulturist at the Royal Rotterdam Zoological and Botanical Gardens. Address: as above.
} 


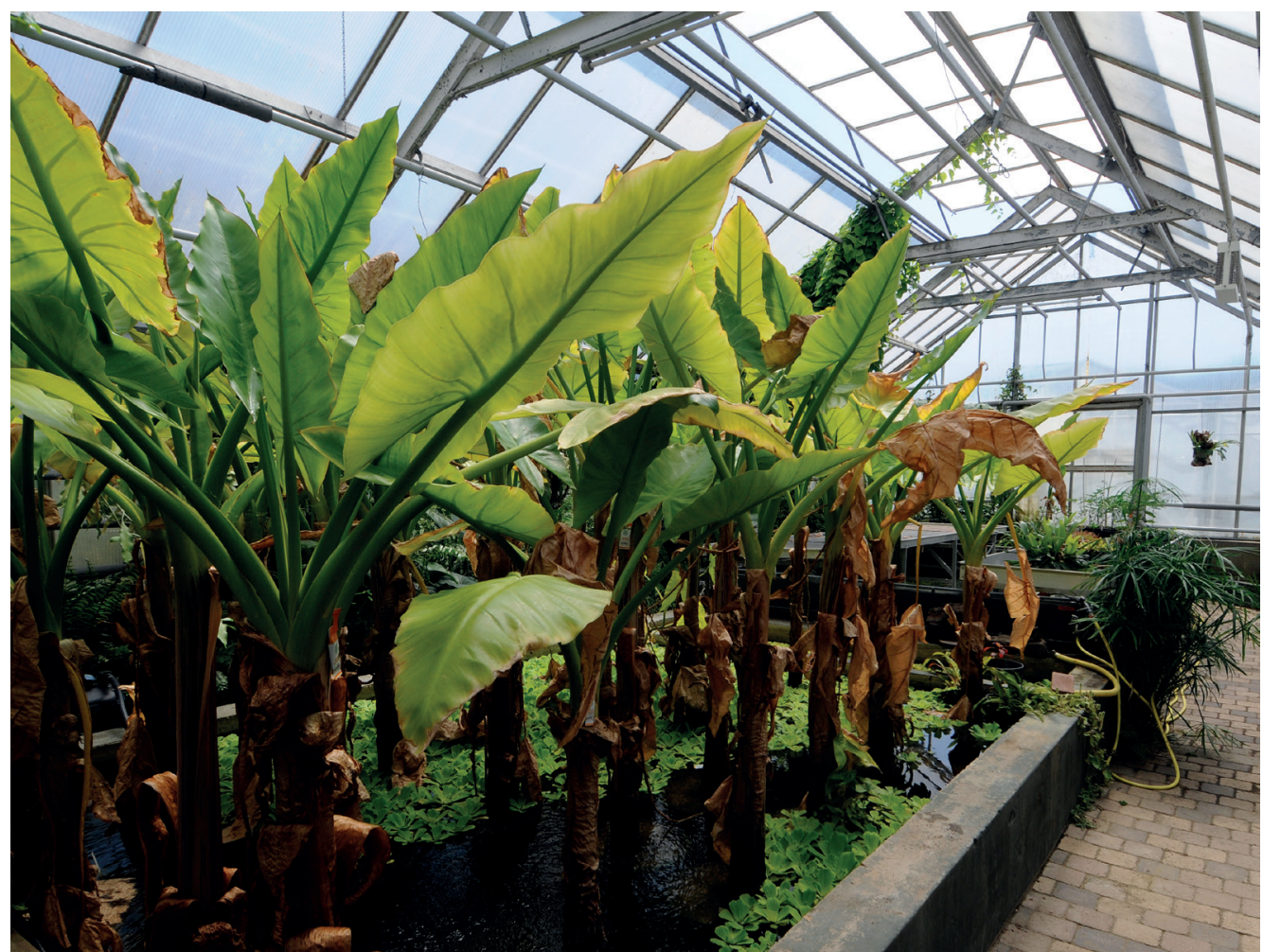

Fig. 1 Typhonodorum lindleyanum (water bananas) at Rotterdam Zoo, Botanical Department. Photo: Rob Doolaard, IZP.

after they die, turn brown and remain clasped around the pseudostem. There are five or six large, upright, subtriangular leaves, $50-90 \mathrm{~cm}$ long and $25 \mathrm{~cm}$ wide, that shoot out of a terminal crown. Adult leaves (Fig. 2) can reach a length of $70-140 \mathrm{~cm}$ and a width of $60 \mathrm{~cm}$ (Govaerts \& Frodin, 2002).

\section{Propagation}

The first ten cleaned seeds and twenty-five seedlings arrived on 16 November 2018. Seed of garden origin was donated by Meise Botanic Garden under the IPEN registration system, a system for botanic gardens to exchange plant genetic resources in compliance with the $\mathrm{CBD}(\mathrm{BGCl}, 2020)$. As soon as the material was unpacked, it was placed in a terrarium with a temperature of $26^{\circ} \mathrm{C}$.

The seedlings had already developed their first leaves and were potted up singly

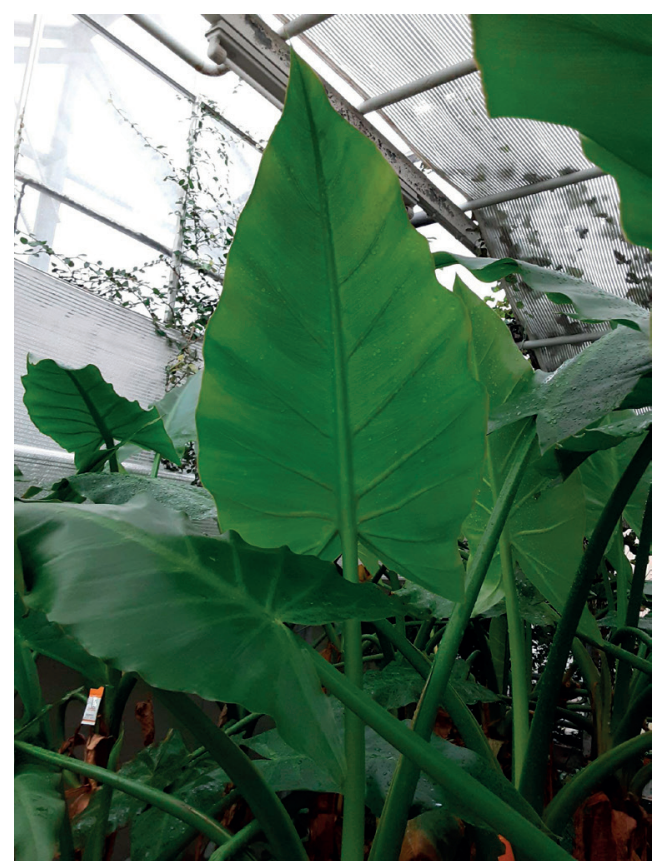

Fig. 2 Close-up of water banana leaf. Photo: Rob Doolaard, IZP. 
into small plastic containers filled with pure loam. These were placed in a tank with the rim of the containers at the same level as the water. These constantly muddy, waterlogged conditions are ideal for Typhonodorum, and rhizomes soon emerged from the holes in the base of the containers. Plants were repotted regularly to maintain steady growth.

The seeds are surrounded by a yellow fleshy pericarp (Fig. 3). Before planting, this was removed manually. The obovoid, greenish-brown, flattened seeds within (Fig. 4) measured $2.5 \times 3 \mathrm{~cm}$ and were approximately $1.5 \mathrm{~cm}$ thick. These were put in a 1-litre tank of warm water at $26^{\circ} \mathrm{C}$ to develop leaves and the first rhizome. When the curved leaves reached a length of $5-8 \mathrm{~cm}$, after four days, they were potted up. The seedlings grew rapidly and developed into small plants within two months (Fig. 5).

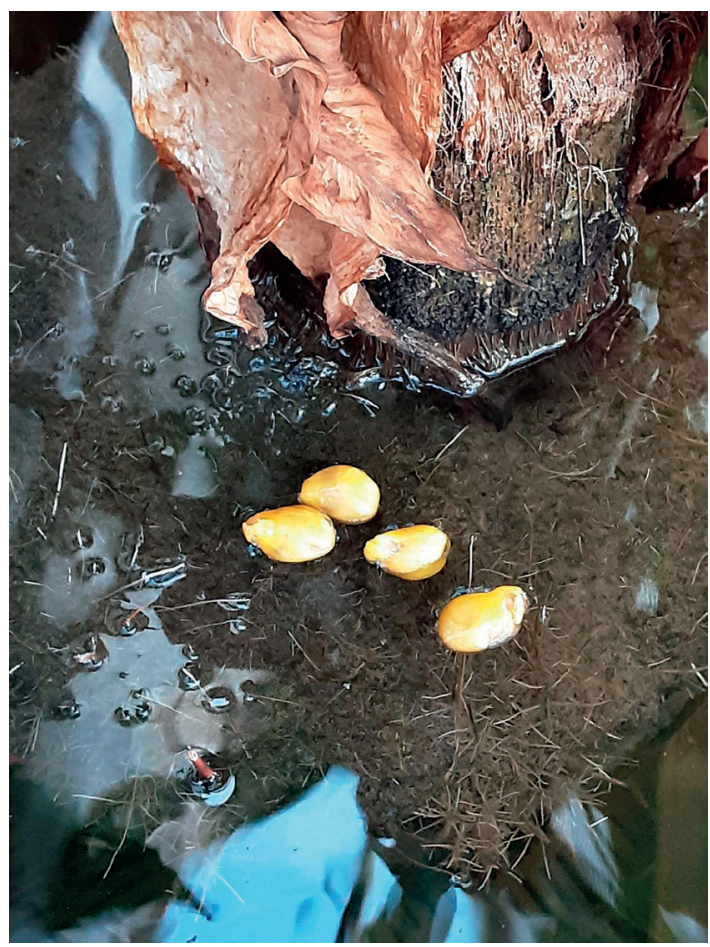

Fig. 3 Seeds in the berries. Photo: L.J. Nederlof.

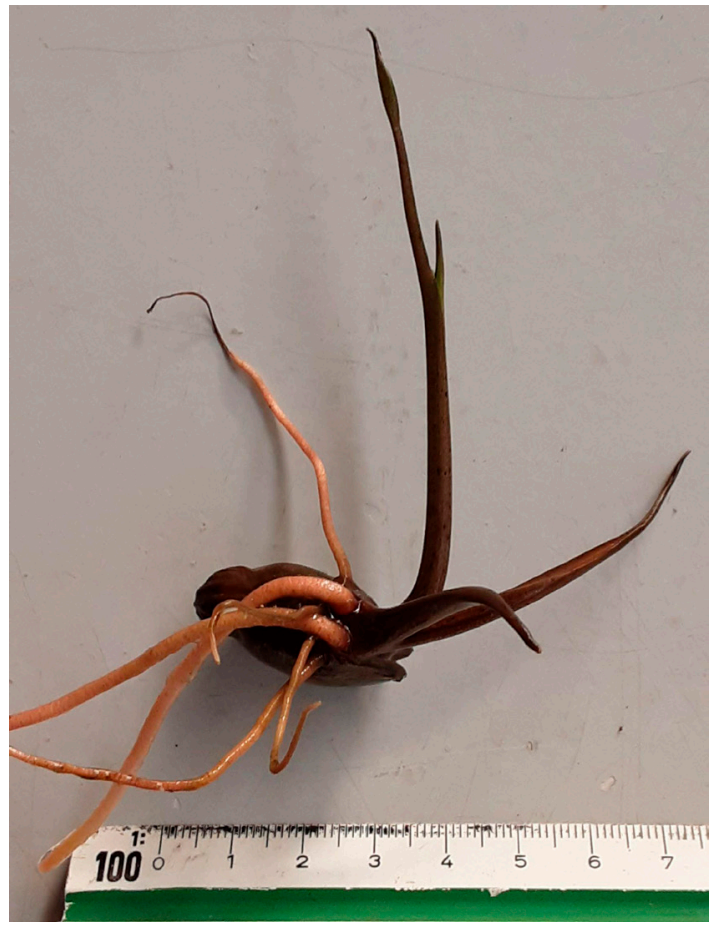

Fig. 5 Seedling after 20 days of development in the nursery. Photo: L.J. Nederlof.

Fig. 4 Seeds ready for planting. Photo: L.J. Nederlof. 
The seeds of Typhnodorum are remarkable in that they are viviparous, and there is no resting stage in the development of the seed from fertilisation to when it becomes a long plumule with two or three leaves that curve towards the apex of the seed (Boodle \& Hill, 1929).

\section{Planting out}

After two months the young plants had reached a height of $40-50 \mathrm{~cm}$. They were then pricked out into a container measuring $36 \times 37 \mathrm{~cm}$ and filled with pure loam. This was placed in the water basin in the tropical greenhouse in the nursery. The water basin measures $3 \times 4 \mathrm{~m}$ and has a depth of $60 \mathrm{~cm}$; the water is maintained at a temperature of $24-26^{\circ} \mathrm{C}$. The basin is connected to an external biofilter with a capacity of 10,000 litres fitted with a Oase BioPress UV unit (available from www.oase-livingwater.com) to prevent the growth of algae in the pond. Finally, the container of seedlings was placed in the basin, with just $2-4 \mathrm{~cm}$ of the pot above the water level. The air temperature of the greenhouse was kept between 24 and $28^{\circ} \mathrm{C}$. In summer, shading material reducing radiation from the sun to 60 per cent is affixed to the internal roof of the greenhouse. Eighteen months after they were planted out as seedlings, the plants had reached a height of $1.5-2.0 \mathrm{~m}$.

\section{General maintenance}

The general maintenance of this aroid is not very difficult if the climate and other conditions in the greenhouse remain stable with a constant temperature and humidity. Once a month during the growing season, from May to October, the young plants were given two or three tablets of Pokon ${ }^{\circledast}$, a slow-release fertiliser containing NPK 10:11:18.
During all stages of growth, the leaves are vulnerable to attack from Tetranychus urticae (red spider mite). The mites were exterminated with Swirski Ulti-Mite, from Koppert Biological Systems, a biological control that contains Amblyseius swirskii, the natural enemy of the spider mite. A second Koppert product, Spidex, containing another predatory mite, Phytoseiulus persimilis, was also used. Populations of Pseudococcus longispinus (woolly balsam aphid) tend to colonise the area between the dead leaves around the pseudostems. These were eradicated by using the natural enemy Anagyrus fusciventris, a small wasp, and the larvae and adults of Cryptolaemus montrouzieri (mealybug ladybird). All of these biological control methods are widely used in northern hemisphere glasshouses heated to tropical temperatures (Ives, 2020).

\section{Flowering and pollination}

The first inflorescence was observed on 25 June 2020 (Fig. 6). The peduncle measured $40-50 \mathrm{~cm}$ in length and $3 \mathrm{~cm}$ in diameter. The plants developed one or two infructescences from one pseudostem in a season. The description of the flowers and anatomy of the Typhonodorum is found in Govaerts \& Frodin (2002).

The spathe was $20-25 \mathrm{~cm}$ long and of a yellowish cream colour, narrowing where the zones of several different male and female flowers join and rolling into a tube at the base.

The upper part and the male part of the spadix desiccate after fertilisation, while the lower part is enclosed by the spathe when fruits develop (Fig. 7).

After flowering, the upright peduncle of the inflorescence gradually turns downwards (Fig. 8). The first infructescence opened on 25 September 2020 and had a length of $17 \mathrm{~cm}$ and a diameter of c. $8 \mathrm{~cm}$. The spathe 


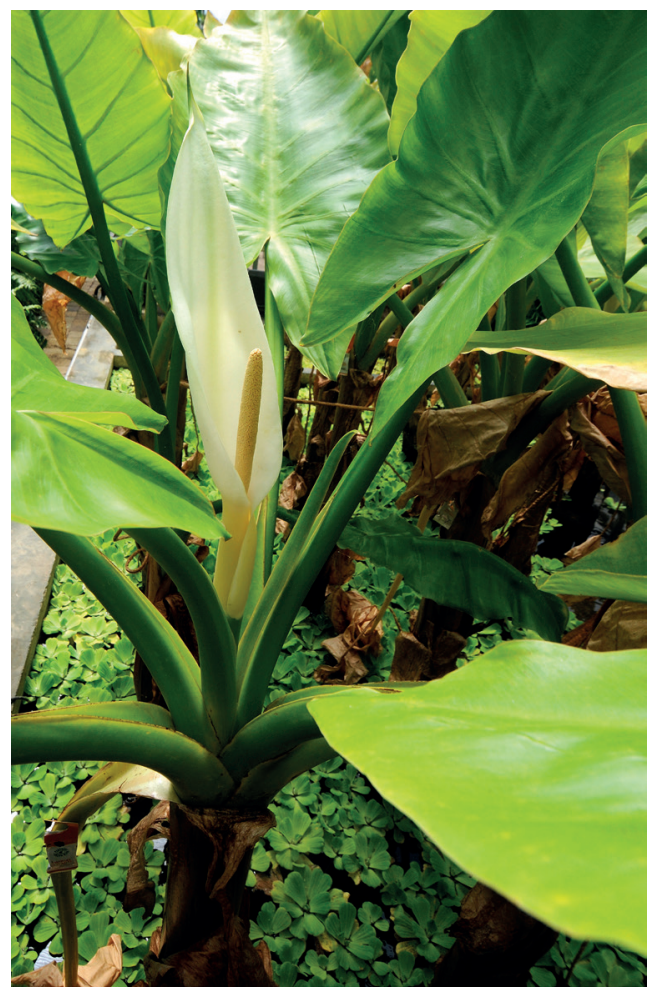

Fig. 6 Inflorescence of Typhnodorum lindleyanum. Photo: Rob Doolaard. remained green but was filled with soft, rotting parenchyma at maturity. It contains 12-20 globose to ovoid, soft, yellow berries with a diameter of $3-4 \mathrm{~cm}$, each containing one seed. The fruits fall into the water as the tip of the spathal chamber opens and releases them. The fruits remain floating on their sides for some time. It seems that the plant flowers and fruits all year round in Madagascar, but in The Netherlands, the flowering season is during the summer months only, from June until October. During the flowering season, twelve inflorescences appeared on at least eight of the adult plants at Rotterdam. Seven inflorescences developed berries; five of them remained unfertilised and many seeds developed by self-pollination. This number might have been higher if the flowers had been pollinated by hand. There was no observation of potential pollinators such as insects in the greenhouse or water basin.

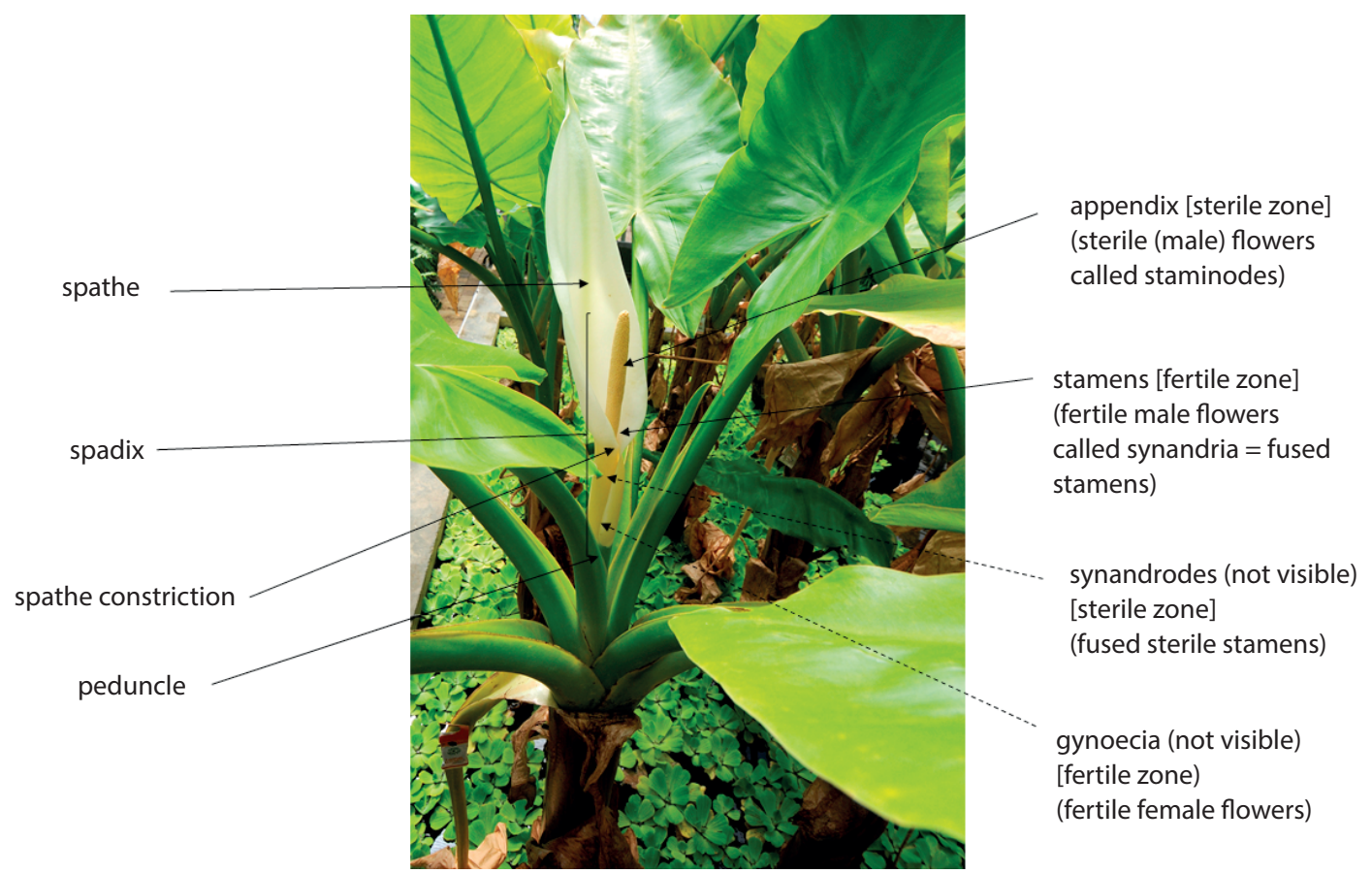

Fig. 7 Location of the male and female flower parts on the spadix. Photo: Marc Gibernau. 


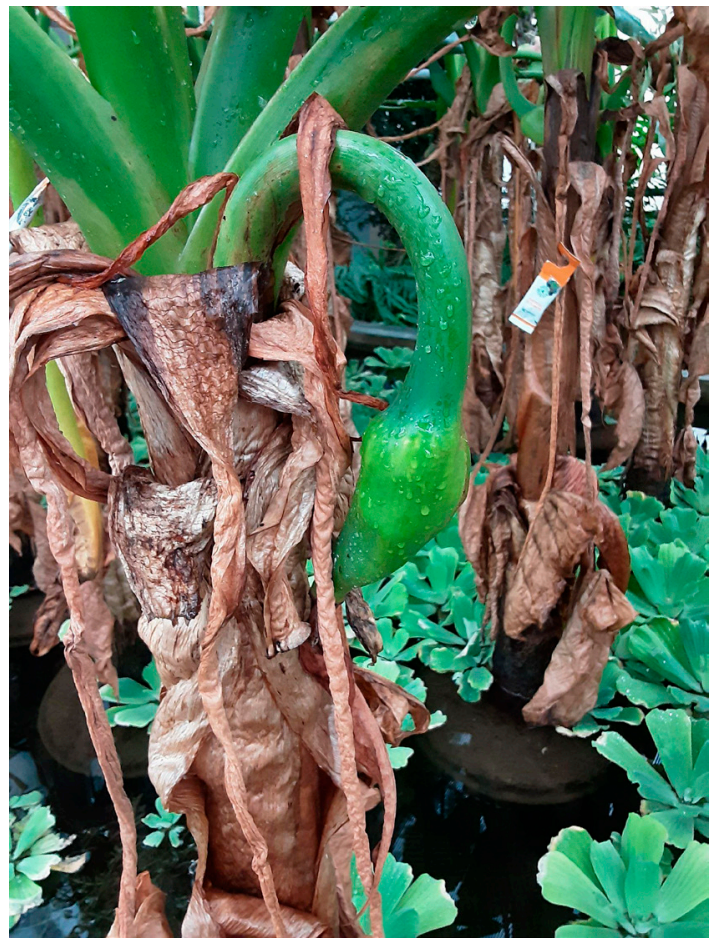

Fig. 8 Downwards bent peduncle. Photo: L.J. Nederlof.

In the coming years, the floral sequence (known as anthesis) of Typhonodorum lindleyanum will be studied in the collection at Rotterdam to better understand the pollination system (Marc Gibernau, pers. comm.). Anthesis is certainly protogynous as it is in all aroids: the stigma is receptive (female phase) and later the pollen is released by the stamens (male phase). The closest phylogenetic genus is the North American endemic Peltandra, which presents a short anthesis summarised as one day of the female phase and two to three days of the male phase. First, we want to observe the flowering sequence by noting the timing of the floral change, requiring a study of stigma wetness and pollen release. Moreover, we will use thermologgers to record inflorescence temperature increase during the anthesis.
Finally, the floral scent will be sampled by Solid Phase Micro Extraction (SPME) Fibers (StableFlexTM SPME Fiber, 65 um PDMS-DVB Coating, Supelco), a non-destructive in situ sampling method, and analysed by gas chromatography to identify its volatile compound constituents.

Water bananas are spectacular plants to exhibit in a tropical greenhouse pond and they are very attractive to the visitors of a zoo or botanic garden. Many aspects of pollination within the Araceae remain unknown (Tom Croat, pers. comm.). There are currently no publications on the pollination of this species (Marc Gibernau, pers. comm.). The collection at Rotterdam Zoo could provide a resource for future research into floral development, thermal activity and scent composition.

In the meantime, visitors can enjoy these spectacular plants as part of the Madagascar display during behind-the-scenes guided tours, and they will form part of the display to be developed in the future.

The horticulturists have learned a lot from growing a species that is new to the collection, and have found it very rewarding to initiate cooperation with other institutions and their collections to reveal the secrets of these intriguing flowering plants.

\section{Acknowledgements}

With thanks to Dr Tom Croat, P.A. Schulze Curator of Botany, Missouri Botanical Garden for his comments and advice on this article.

Thanks to Marc Gibernau, Senior Researcher with the Centre National de la Recherche Scientifique/French National Centre for Scientific Research, University of Corsica, Ajaccio, France, for creating Fig. 7 with the outline of the flower types and anatomy of Typhonodorum. 


\section{References}

BGCI, (2020). The International Plant Exchange Network. Available online: https://www.bgci.org/ our-work/policy-and-advocacy/access-and-benefitsharing/the-international-plant-exchange-network/ (accessed January 2021).

BOODLE, L.A. \& HILL, A.W. (1929).

Typhonodorum lindleyanum: the development of the embryo and germination of the seed. Annals of Botany, 43(3): 437-450, https://doi.org/10.1093/ oxfordjournals.aob.a090180

GOVAERTS, R. \& FRODIN, D.G. (2002). Plants of the World Online, Kew Science World Checklist and
Bibliography of Araceae (and Acoraceae). Royal Botanic Gardens, Kew. Available online: www. plantsoftheworldonline.org (accessed January 2021). IVES, J. (2020). Biological controls in botanic gardens. Sibbaldia, 18: 117-125, https://doi. org/10.24823/Sibbaldia.2020.292

MAYO, S.J., BOGNER, J. \& BOYCE, P.C. (1997). The Genera of Araceae. Royal Botanical Gardens, Kew.

SHAW, D.E. (1990). Germination of Typhonodorum lindleyanum at Brisbane, Australia. Aroideana, 13(1-4): 14-20.

WOURMS, M.K. (1990). Zoo exhibits and the role of zoo horticulture. International Zoo Yearbook, 29: 3-6. 